\title{
Hemodynamic Assessment and Support in Sepsis and Septic Shock in Resource-Limited Settings
}

\author{
David Misango, Rajyabardhan Pattnaik, Tim Baker, \\ Martin W. Dünser, Arjen M. Dondorp, \\ and Marcus J. Schultz
}

\subsection{Introduction}

Recommendations for care in patients with sepsis or septic shock are largely based on evidence originating from resource-rich settings [1]. It is increasingly appreciated that these recommendations cannot be directly generalized to resource-limited

D. Misango

Department of Anaesthesiology and Critical Care Medicine, Aga Khan University Hospital, Nairobi, Kenya

R. Pattnaik

Department of Intensive Care Medicine, Ispat General Hospital, Rourkela, Sundargarh, Odisha, India

T. Baker

Department of Anesthesia, Intensive Care and Surgical Services, Karolinska University Hospital, Stockholm, Sweden

Department of Public Health Sciences, Karolinska Institutet, Stockholm, Sweden

M. W. Dünser $(\bowtie)$

Department of Anesthesia and Intensive Care, Kepler University Hospital, Johannes Kepler University Linz, Linz, Austria

A. M. Dondorp

Mahidol-Oxford Tropical Medicine Research Unit (MORU), Faculty of Tropical Medicine, Mahidol University, Bangkok, Thailand

Nuffield Department of Clinical Medicine, Oxford Centre for Tropical Medicine and Global Health, University of Oxford, Oxford, UK

Department of Intensive Care, Academic Medical Center, Amsterdam, The Netherlands

M. J. Schultz

Mahidol-Oxford Tropical Medicine Research Unit (MORU), Faculty of Tropical Medicine, Mahidol University, Bangkok, Thailand

Department of Intensive Care, Academic Medical Center, Amsterdam, The Netherlands

(C) The Author(s) 2019

A. M. Dondorp et al. (eds.), Sepsis Management in Resource-limited Settings, https://doi.org/10.1007/978-3-030-03143-5_7 
settings for several reasons, including restrictions in human and material resources but also concerns regarding costs and safety [2, 3]. It is even possible that the efficacy and effectiveness of certain strategies differ between resource-rich and resource-limited settings. Indeed, efficacy and effectiveness could depend on the type of sepsis, and it is well known that non-bacterial sepsis is much more common in resource-limited than in resource-rich settings [3].

In this chapter, we aim to answer five practical questions regarding hemodynamic assessment and support in sepsis and septic shock in resource-limited settings. As recognition of hypoperfusion and return to normal perfusion, and detection of fluid responsiveness, could avoid under- and over-resuscitation as well as underand overuse of vasoactive agents, (1) there is need for affordable bedside tools for tissue perfusion monitoring and (2) a better understanding of practicalities of passive leg raise tests in these settings; as costs and availability of, but also indications for, intravenous fluids could be different in resource-limited settings, (3) advises regarding the preferable type of intravenous fluid to be used during fluid resuscitation, as well as (4) amounts and timing of intravenous fluids for sepsis shock in resource-limited ICUs, are essential. Finally, seen the limited availability of vasopressors and inotropes, and the risks associated with their use, (5) recommendations on their indications, titrations, and ways of administration in settings with limited resources are highly necessary. Recommendations and suggestions are summarized in Table 7.1.

\subsection{Simple Bedside Tools to Assess Tissue Perfusion}

Timely detection of tissue hypoperfusion is one crucial aspect of hemodynamic assessment in patients with sepsis or septic shock. Several studies showed that capillary refill times $>5 \mathrm{~s}$ following initial hemodynamic optimization are associated with worsening organ failures [4-6]. Normalization of capillary refill time was prognostic of survival in septic shock patients [7]. During early septic shock, capillary refill time was found to be a good predictor of short-term mortality [8] and related to perfusion of the liver, spleen, kidneys, and intestines in adults [9]. There was noticeable variation, though, in how capillary refill times were checked, at least in investigations involving children (Table 7.2), and several factors may affect the accuracy capillary refill time, like the ambient temperature and light, the site of measurement, and the amount of pressure applied to the capillary bed [10]. There was debate on whether capillary refill time is subject to interobserver variability [10, 11]. One study in India suggests capillary refill time to be insensitive to detect tissue hypoperfusion in patients with malaria [12].

Mottling, patchy skin discolorations due to heterogenic small-vessel vasoconstriction that usually start around the knees and elbows in patients with shock could also reflect abnormal skin perfusion. A simply to apply at the bedside score, using a scale from 0 ("no mottling") to 5 ("grave mottling") (Table 7.3 and Fig. 7.1) related 
Table 7.1 Recommendations for fluid management and hemodynamic support in patients with sepsis or septic shock in resource-limited settings (with grading)

\begin{tabular}{|c|c|c|}
\hline 1 & $\begin{array}{l}\text { Simple bedside tools } \\
\text { to assess tissue } \\
\text { perfusion }\end{array}$ & $\begin{array}{l}\text { We suggest using capillary refill time, skin mottling scores, and, if } \\
\text { affordable, skin temperature gradients to assess adequacy of tissue } \\
\text { perfusion in pediatric and adult sepsis and septic shock, either alone } \\
\text { or in combination (UG). It remains uncertain whether these tools } \\
\text { are effective in severe malaria. These tools are noninvasive and safe } \\
\text { and come at no additional or low costs, though costs of temperature } \\
\text { probes could still be too high for certain resource-limited settings. } \\
\text { This recommendation remains weak, mainly because of the absence } \\
\text { of evidence that these bedside tools can adequately guide important } \\
\text { decisions in hemodynamic support }\end{array}$ \\
\hline 2 & $\begin{array}{l}\text { The passive leg raise } \\
\text { test and other simple } \\
\text { tools to replace } \\
\text { direct measurements } \\
\text { of cardiac output }\end{array}$ & $\begin{array}{l}\text { We suggest using the passive leg raise test to guide fluid } \\
\text { resuscitation in sepsis or septic shock in resource-limited settings } \\
(2 \mathrm{~A}) \text {. It is uncertain whether the passive leg raise test has predictive } \\
\text { values in all types of sepsis and septic shock, like in severe malaria } \\
\text { or severe dengue. We suggest using the passive leg raise test in } \\
\text { children but only in those above the age of } 5 \text { (2C). We recommend } \\
\text { direct measurement of changes in cardiac output when performing a } \\
\text { passive leg raise test (1C) and suggest using changes in pulse } \\
\text { pressure if the former is not possible ( } 2 \mathrm{C})\end{array}$ \\
\hline 3 & Fluid strategies & $\begin{array}{l}\text { We recommend crystalloid solutions as the initial fluid of choice in } \\
\text { patients with bacterial severe sepsis or septic shock (1B) and } \\
\text { recommend against the use of synthetic colloid solutions (1B). We } \\
\text { recommend the same for patients with severe falciparum malaria } \\
\text { (1B). We also recommend using crystalloids and not colloids in } \\
\text { severe dengue with compensated shock for initial fluid } \\
\text { resuscitation (1B), but there is insufficient evidence to recommend } \\
\text { fluid choices in severe dengue with hypotensive shock. In order to } \\
\text { avoid delays in initial resuscitation, it is advisable that wards } \\
\text { carrying for patients with sepsis or septic shock stockpile } \\
\text { crystalloid solutions for their immediate availability, to avoid } \\
\text { delaying initial fluid resuscitation (UG) }\end{array}$ \\
\hline 4 & $\begin{array}{l}\text { Amounts and timing } \\
\text { of IV fluids }\end{array}$ & $\begin{array}{l}\text { We recommend that fluid resuscitation is initiated in patients with } \\
\text { sepsis and suspected hypovolemia as early as possible, ideally } \\
\text { within the first } 30 \mathrm{~min} \text { after recognition, and to start with } 30 \mathrm{~mL} / \mathrm{kg} \\
\text { over the first } 3 \mathrm{~h}(1 \mathrm{~A}) \text {. Larger amounts of fluid may be needed in } \\
\text { patient that remains fluid responsive (e.g., according to the results } \\
\text { of a passive leg raise test) and still shows signs of tissue } \\
\text { hypoperfusion (e.g., according to the capillary refill time, the skin } \\
\text { mottling score, or skin temperature gradients) (1C). We recommend } \\
\text { being extremely cautious and thus more conservative in patients in } \\
\text { settings with no or limited access to vasopressors and mechanical } \\
\text { ventilation, where consideration should be given to stopping fluid } \\
\text { administration if the patient develops signs of respiratory distress or } \\
\text { lung crepitations on chest auscultation (1A). This also applies for } \\
\text { fluid resuscitation in children (1A). Patients with severe malaria or } \\
\text { severe dengue without hypotension should not receive fluid bolus } \\
\text { therapy }\end{array}$ \\
\hline
\end{tabular}


Table 7.1 (continued)

5 Vasopressors and inotropes
We recommend against the start of a vasopressor before initial fluid resuscitation, especially when a central line cannot be used (1C). We suggest starting a vasopressor in patients with persistent arterial hypotension (2C) and recommend targeting a mean arterial blood pressure $\geq 65 \mathrm{mmHg}$ (1B). We recommend using norepinephrine (noradrenaline) as first-line vasopressor (1B) and suggest using dopamine if norepinephrine is not available (2B). The target for titration of inotropic drugs could be normalization of plasma lactate levels $(<2 \mathrm{mmol} / \mathrm{L})$ or normalization of capillary refill time $(<3 \mathrm{~s})$ or reduction in skin mottling (UG) if plasma lactate levels cannot be measured. We suggest using dobutamine as first-line inotrope (2B) and epinephrine (adrenaline) if dobutamine is not available (2B). We recommend administering vasopressors via a central venous line (1C) and suggest titrations of vasopressors and inotropes using a syringe or infusion pump when available (2D)

Abbreviation: $U G$ ungraded

Table 7.2 Different methods of measuring and interpreting capillary refill time in children

\begin{tabular}{l|l}
\hline Method & Interpretation \\
\hline $\begin{array}{l}\text { Apply pressure to the nail bed or other area with } \\
\text { visible circulation; measure the length of time it } \\
\text { takes for blanching to disappear }\end{array}$ & $\begin{array}{l}\text { A capillary refill time }<2 \mathrm{~s} \text { is normal; }>4 \mathrm{~s} \\
\text { is abnormal; a capillary refill time } \\
\text { between } 2 \text { and } 4 \mathrm{~s} \text { should prompt further } \\
\text { consideration of the presence of shock }\end{array}$ \\
\hline $\begin{array}{l}\text { The preferred location to test capillary refill time } \\
\text { is sternum; if finger or toe is used, leg or arm must } \\
\text { be elevated; press firmly for 5 } \mathrm{s}\end{array}$ & $\begin{array}{l}\text { A capillary refill time }>5 \mathrm{~s} \text { indicates an } \\
\text { inadequate cardiac output }\end{array}$ \\
\hline $\begin{array}{l}\text { After fingertip pressure to a distal extremity, } \\
\text { blood should refill the area within less than } 2 \mathrm{~s} \\
\text { after release }\end{array}$ & $\begin{array}{l}\text { A capillary refill time }>2 \mathrm{~s} \text { in the setting of } \\
\text { other signs of shock indicates a } \\
\text { compensated shock state }\end{array}$ \\
\hline $\begin{array}{l}\text { Press on sternum or digit at the level of the heart } \\
\text { for } 5 \mathrm{~s}\end{array}$ & $\begin{array}{l}\text { A capillary refill time }>2 \mathrm{~s} \text { is a clinical } \\
\text { feature of shock }\end{array}$ \\
$\begin{array}{l}\text { Cutaneous pressure on the sternum or on a digit } \\
\text { for } 5 \mathrm{~s}\end{array}$ & $\begin{array}{l}\text { A slower refill than } 2 \mathrm{~s} \text { can indicate poor } \\
\text { skin perfusion, a sign which may be } \\
\text { helpful in early septic shock }\end{array}$ \\
$\begin{array}{l}\text { Grasp the child's thumb or big toe between the } \\
\text { finger and thumb and look at the pink of the nail } \\
\text { bed; apply minimal pressure necessary for } 3 \mathrm{~s} \text { to } \\
\text { produce blanching of the nail bed; time the } \\
\text { capillary refill from the moment of release until } \\
\text { total return of the pink color }\end{array}$ & $\begin{array}{l}\text { Capillary refill time should be }<3 \mathrm{~s} \text {; if }>3 \mathrm{~s} \\
\text { the child may have a problem with shock }\end{array}$ \\
\hline
\end{tabular}

Adapted and modified from Pandey et al. [37]

well to plasma lactate levels, urine output, degree of organ dysfunctions, and even mortality in patients with septic shock [13]. Patients whose mottling score decreased during the resuscitation period had a better prognosis [13]. The prognostic value of this score was confirmed in other cohorts of critically ill patients $[14,15]$. The mottling score had a good reproducibility and did not suffer from interobserver variability [13]. 
Table 7.3 Skin mottling score after initial fluid resuscitation

\begin{tabular}{l|l|l}
\hline Score & & Description \\
\hline 0 & No & No mottling \\
\hline 1 & Modest & Coin size-localized to the center of the knee \\
\hline 3 & Moderate & Mottling does not exceed the superior edge of the kneecap \\
\hline 4 & Mild & Mottling does not exceed the middle thigh \\
\hline 5 & Severe & Mottling does not exceed beyond the fold of the groin \\
\hline
\end{tabular}

Adapted from Ait-Oufella et al. [13]

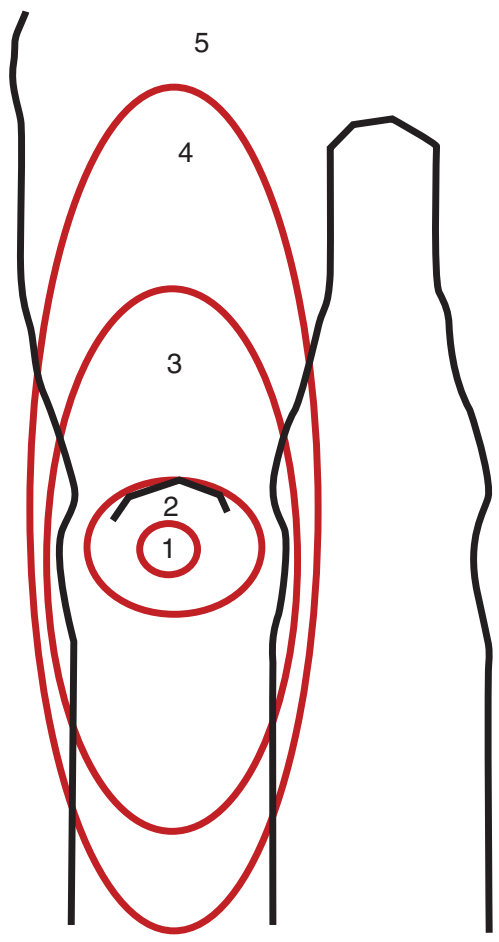

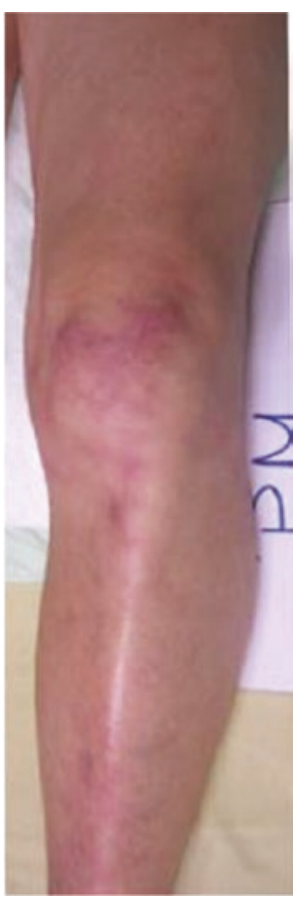

SCORE 2

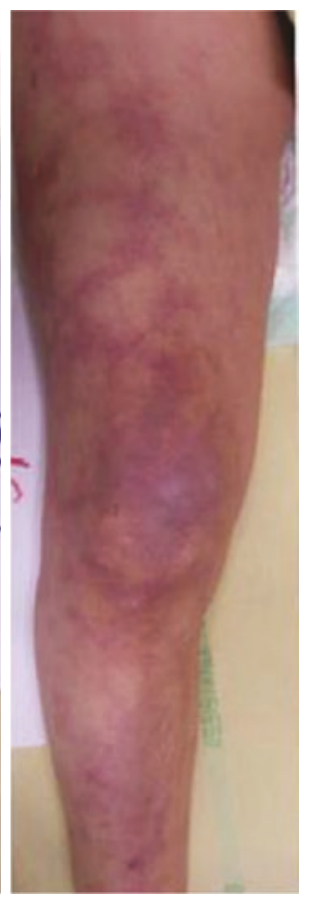

SCORE 4

Fig. 7.1 Skin mottling score; from Ait-Oufella et al. [13]

Skin temperature gradients, the difference between two different measurement points, such as between the forearm and fingertip, or the central and toe, could be useful in detecting changes in skin perfusions in sepsis and septic shock $[16,17]$. The advantage of using skin temperature gradients between the forearm and fingertip, instead of a single skin temperature, is that both spots are similarly affected by ambient temperature. The normal skin temperature gradient between forearm and fingertip is $0{ }^{\circ} \mathrm{C}$. Skin temperature gradients between the forearm and fingertip of $>4{ }^{\circ} \mathrm{C}$ were associated with severe vasoconstriction. Increased skin temperature gradient was related to the outcome of sepsis [18]. 
We suggest using capillary refill time, skin mottling scores, and, if affordable, skin temperature gradients to assess adequacy of tissue perfusion in pediatric and adult sepsis and septic shock, either alone or in combination (UG). It remains uncertain whether these tools are effective in malaria. These tools are noninvasive and safe and come at no additional or low costs, though costs of temperature probes could still be too high for certain resource-limited settings. This recommendation remains weak, mainly because of the absence of evidence that these bedside tools can adequately guide important decisions in hemodynamic support.

\subsection{The Passive Leg Raise Test and Other Simple Tools to Replace Direct Measurements of Cardiac Output}

If it is decided that a patient is hypovolemic, it should also be determined whether that patients is "fluid responsive." The method for performing passive leg raise test is important because it fundamentally affects its hemodynamic effects and reliability [19]. The test needs to be executed so that it does not result in pain and anxiety as this may influence the results. Furthermore, a proper passive leg raise test consists lifting the bed at the foot end and not lifting the legs (Fig. 7.2). The latter could be a challenge in resource-limited settings where beds are usually not easy adjustable. While it is best to use a direct measure of cardiac output or stroke volume, this is frequently impossible in settings where resources are low. A less accurate but still acceptable approach is to detect changes in pulse pressure. The test then starts with an initial (noninvasive) blood pressure measurement-after 60-90 s of passively raising the legs, the blood pressure measurement is repeated-and a change in the difference between systolic and diastolic pressure $>15 \%$ could indicate that the patient is "fluid responsive" [20].

It remains uncertain whether the passive leg raise test has comparable predictive values in various types of sepsis and septic shock, e.g., in severe malaria or severe dengue, as literature is lacking. This could actually be seen as one major objection against widespread use of passive leg raise tests in resource-limited settings. This is also true for young children. So far, only one preliminary study suggests that a

SEMI-RECUMBANT POSITION

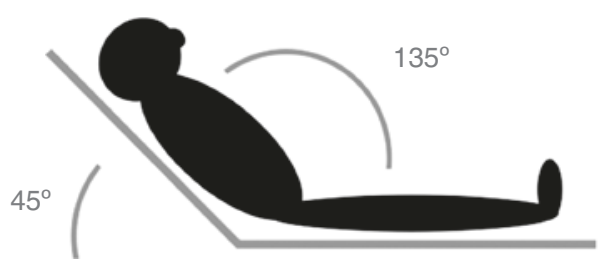

PASSIVE LEG RAISE POSITION

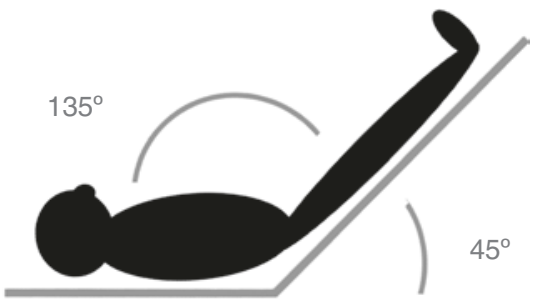

Fig. 7.2 For maximal reliability, a passive leg raise test should be performed following some rules. One possible variation of test starts from the semi-recumbent position. The second step comprises to go down the trunk and raise legs maintaining the angle between them using the automatic motion of the bed for avoiding artifacts. Finally the third step goes back to the semirecumbent position to ensure that the subject recovers the previous hemodynamic parameters 
passive leg raise test is helpful in predicting fluid responsiveness in children but not in those under 5 years of age [21].

We suggest using the passive leg raise test to guide fluid resuscitation in sepsis or septic shock in resource-limited settings (2A). It is uncertain whether the passive leg raise test has predictive values in all types of sepsis and septic shock, like in severe malaria or severe dengue. We suggest using the passive leg raise test and in children but only in those above the age of 5 (2C). We recommend direct measurement of changes in cardiac output when performing a passive leg raise test (1C) and suggest using changes in pulse pressure if the former is not possible (2C).

\subsection{Fluid Strategies}

There is a large body of literature from resource-rich settings on the choice of fluids in severe sepsis and septic shock, with a strong focus on sepsis caused by bacterial pathogens. The theoretical benefits of colloid solutions over crystalloids, with better retention in the intravascular compartment, have not translated to better outcomes with colloids for the treatment of severe sepsis of septic shock in randomized clinical trials performed in resource-rich settings. In addition, synthetic colloid solutions have shown important adverse effects, in particular nephrotoxicity with the use of starch solutions. Consequently, the Surviving Sepsis Campaign makes a strong recommendation for the use of crystalloid solutions over colloids for fluid resuscitation [1].

The "Fluid Expansion as Supportive Therapy" trial in children in sub-Saharan Africa with compensated septic shock, of which $57 \%$ had severe falciparum malaria, showed a detrimental effect of saline bolus as well as albumin bolus therapy compared to a more conservative fluid therapy [22]. The study supersedes earlier small studies suggesting a survival benefit of albumin infusion over crystalloids in children with severe falciparum malaria and severe sepsis [23, 24].

Three randomized trials in patients with dengue shock syndrome did not show better outcome parameters with (more expensive) colloids over crystalloid fluids [25-27]. A quasi-randomized study from the Philippines alternating allocation of colloids with crystalloids also did not show an additional benefit of colloids [28].

From the task force members' experience, it is important that in wards caring for critically ill patients, intravenous fluids are stockpiled so that they are immediately available for emergency treatment, to save time and to prevent incurring additional costs for the patient's family.

We recommend crystalloid solutions as the initial fluid of choice in patients with bacterial severe sepsis or septic shock (1B) and recommend against the use of synthetic colloid solutions (1B). We recommend the same for patients with severe falciparum malaria (1B). We also recommend using crystalloids and not colloids in severe dengue with compensated shock for initial fluid resuscitation (1B), but there is insufficient evidence to recommend fluid choices in severe dengue with hypotensive shock. In order to avoid delays in initial resuscitation, it is advisable that wards carrying for patients with sepsis or septic shock stockpile crystalloid solutions for their immediate availability, to avoid delaying initial fluid resuscitation (UG). 


\subsection{Amounts and Timing of IV Fluids}

A landmark study from an emergency department in a resource-rich setting found that so-called early goal-directed therapy, in which intravenous fluids were given to swiftly have physiological parameters return to pre-defined levels, reduced mortality by as much as a third [29]. Early goal-directed therapy has since become mainstream practice in the treatment of critically ill patients. The Surviving Sepsis Campaign recommends that, in the resuscitation from sepsisinduced hypoperfusion, at least $30 \mathrm{ml} / \mathrm{kg}$ of intravenous crystalloid fluid be given within the first $3 \mathrm{~h} \mathrm{[1].}$

The largest fluid trial performed in resource-limited settings is the above-cited FEAST trial in children [22]. This trial showed an alarming increase in mortality with bolus intravenous infusion in critically ill children. There is an ongoing debate whether mortality increased because of development of pulmonary fluid overload, which could not be compensated for by mechanical ventilation; a secondary analysis of FEAST exploring whether boluses may have caused excess deaths from fluid overload actually suggested cardiovascular collapse rather than fluid overload appeared to contribute most to excess deaths with rapid fluid resuscitation [30]. Nevertheless, similar alarming findings come from several studies in adult patients in resource-limited settings [31-34]. The most recent trial clearly showed a protocol for early resuscitation with administration of intravenous fluids and vasopressors to increase mortality [34]. The absolute or relative absence of vasopressors and maybe mechanical ventilation could make fluid loading too dangerous.

We recommend that fluid resuscitation is initiated in patients with sepsis and suspected hypovolemia as early as possible, ideally within the first 30 min after recognition, and to start with $30 \mathrm{ml} / \mathrm{kg}$ over the first $3 \mathrm{~h}(1 \mathrm{~A})$. Larger amounts of fluid may be needed in patient that remains fluid responsive (e.g., according to the results of a passive leg raise test) and still shows signs of tissue hypoperfusion (e.g., according to the capillary refill time, the skin mottling score, or skin temperature gradients) (1C). We recommend being extremely cautious and thus more conservative in patients in settings with no or limited access to vasopressors and mechanical ventilation, where consideration should be given to stopping fluid administration if the patient develops signs of respiratory distress or lung crepitations on chest auscultation (1A). This also applies for fluid resuscitation in children (1A). Patients with severe malaria or severe dengue without hypotension should not receive fluid bolus therapy (see Chap. 9).

\subsection{Vasopressors and Inotropes}

The Surviving Sepsis Campaign recommends norepinephrine as the first-choice vasopressor and adding epinephrine to norepinephrine with the intent of raising MAP to target, to decrease norepinephrine dosage. The Surviving Sepsis Campaign also suggests using dopamine as an alternative vasopressor only in selected patients 
and using dobutamine in patients who show evidence of persistent hypoperfusion despite adequate fluid loading and the use of vasopressors [1].

Extravasation of vasopressors causes skin necrosis, and extravasation is more likely with administration through a peripheral infusion line compared to central venous administration. Central venous catheters, however, are frequently not available, expensive, and inserted too late and frequently require extra payments by family members of the patient further delaying its use. Administration of vasopressors is thus frequently done through a peripheral line. We consider it reasonable to await the effect of initial fluid resuscitation before starting infusion of vasopressors through a peripheral infusion line, but in patients with extreme low blood pressure, and in those not immediately responding to initial fluid loading, it could be necessary to continue without a central venous catheter. Additional advantages of a central venous line are that it can also be used for repeated blood sampling, measurement of static hemodynamic measures, and where possible follow-up of central venous oxygenation.

Vasopressors and inotropes have a narrow therapeutic window, necessitating accurate dosing. Continuous administration at exact doses is safeguarded preferably by automatic infusion with a syringe or infusion pump. Although less accurate, when syringe pumps are not available, these drugs can be diluted in normal saline and administered using a mechanical drop counter.

Norepinephrine is not generally available in hospitals with limited resources. Dopamine is more widely available, but reported best access in resource-limited settings is to epinephrine. We prefer dopamine to epinephrine as the latter may cause lactate acidosis [35, 36]. In resource-limited settings, dobutamine is only available in selected regions, and stockouts of the drug are very common.

Titration of inotropes in resource-limited ICUs is a challenge, as assessed by means of plasma lactate levels is expensive and frequently not possible. Capillary refill time $(<3 \mathrm{~s})$ and the skin mottling score can be used to evaluate the effect of infusion of vasopressors and inotropes, but there is no documented evidence regarding efficacy or safety. Of note, vasopressors can affect capillary refill time and skin mottling scores.

We recommend against the start of a vasopressor before initial fluid resuscitation, especially when a central line cannot be used (1C). We suggest starting a vasopressor in patients with persistent arterial hypotension (2C) and recommend targeting a mean arterial blood pressure $\geq 65 \mathrm{mmHg}$ (1B). We recommend using norepinephrine (noradrenaline) as first-line vasopressor (1B) and suggest using dopamine if norepinephrine is not available (2B). The target for titration of inotropic drugs could be normalization of plasma lactate levels $(<2 \mathrm{mmol} / \mathrm{L})$ or normalization of capillary refill time $(<3 \mathrm{~s})$ or reduction in skin mottling (UG) if plasma lactate levels cannot be measured. We suggest using dobutamine as first-line inotrope (2B) and epinephrine (adrenaline) if dobutamine is not available (2B). We recommend administering vasopressors via a central venous line (1C) and suggest titrations of vasopressors and inotropes using a syringe or infusion pump when available (2D). 


\subsection{Conclusions}

The paucity of evidence from resource-limited settings and in specific types of sepsis and septic shock underscores the urgent need for rigorous trials, since efficacy and effectiveness of commonly used interventions in resource-rich settings could differ importantly in resource-limited settings.

\section{References}

1. Rhodes A, Evans LE, Alhazzani W, Levy MM, Antonelli M, Ferrer R, Kumar A, Sevransky JE, Sprung CL, Nunnally ME, Rochwerg B, Rubenfeld GD, Angus DC, Annane D, Beale RJ, Bellinghan GJ, Bernard GR, Chiche JD, Coopersmith C, De Backer DP, French CJ, Fujishima S, Gerlach H, Hidalgo JL, Hollenberg SM, Jones AE, Karnad DR, Kleinpell RM, Koh Y, Lisboa TC, Machado FR, Marini JJ, Marshall JC, Mazuski JE, McIntyre LA, McLean AS, Mehta S, Moreno RP, Myburgh J, Navalesi P, Nishida O, Osborn TM, Perner A, Plunkett CM, Ranieri M, Schorr CA, Seckel MA, Seymour CW, Shieh L, Shukri KA, Simpson SQ, Singer M, Thompson BT, Townsend SR, Van der Poll T, Vincent JL, Wiersinga WJ, Zimmerman JL, Dellinger RP. Surviving Sepsis Campaign: International Guidelines for Management of Sepsis and Septic Shock: 2016. Crit Care Med. 2017;45:486-552.

2. Arabi YM, Schultz MJ, Salluh JIF. Intensive Care Medicine in 2050: global perspectives. Intensive Care Med. 2017;43:1695-9.

3. Schultz MJ, Dunser MW, Dondorp AM, Adhikari NK, Iyer S, Kwizera A, Lubell Y, Papali A, Pisani L, Riviello BD, Angus DC, Azevedo LC, Baker T, Diaz JV, Festic E, Haniffa R, Jawa R, Jacob ST, Kissoon N, Lodha R, Martin-Loeches I, Lundeg G, Misango D, Mer M, Mohanty S, Murthy S, Musa N, Nakibuuka J, Serpa Neto A, Nguyen Thi Hoang M, Nguyen Thien B, Pattnaik R, Phua J, Preller J, Povoa P, Ranjit S, Talmor D, Thevanayagam J, Thwaites CL, Global Intensive Care Working Group of the European Society of Intensive Care Medicine. Current challenges in the management of sepsis in ICUs in resource-poor settings and suggestions for the future. Intensive Care Med. 2017;43:612-24.

4. Hernandez G, Pedreros C, Veas E, Bruhn A, Romero C, Rovegno M, Neira R, Bravo S, Castro R, Kattan E, Ince C. Evolution of peripheral vs metabolic perfusion parameters during septic shock resuscitation. A clinical-physiologic study. J Crit Care. 2012;27:283-8.

5. Lima A, Jansen TC, van Bommel J, Ince C, Bakker J. The prognostic value of the subjective assessment of peripheral perfusion in critically ill patients. Crit Care Med. 2009;37:934-8.

6. van Genderen ME, Lima A, Akkerhuis M, Bakker J, van Bommel J. Persistent peripheral and microcirculatory perfusion alterations after out-of-hospital cardiac arrest are associated with poor survival. Crit Care Med. 2012;40:2287-94.

7. Hernandez G, Luengo C, Bruhn A, Kattan E, Friedman G, Ospina-Tascon GA, Fuentealba A, Castro R, Regueira T, Romero C, Ince C, Bakker J. When to stop septic shock resuscitation: clues from a dynamic perfusion monitoring. Ann Intensive Care. 2014;4:30.

8. Ait-Oufella H, Bige N, Boelle PY, Pichereau C, Alves M, Bertinchamp R, Baudel JL, Galbois A, Maury E, Guidet B. Capillary refill time exploration during septic shock. Intensive Care Med. 2014;40:958-64.

9. Brunauer A, Kokofer A, Bataar O, Gradwohl-Matis I, Dankl D, Bakker J, Dunser MW. Changes in peripheral perfusion relate to visceral organ perfusion in early septic shock: a pilot study. J Crit Care. 2016;35:105-9.

10. King D, Morton R, Bevan C. How to use capillary refill time. Arch Dis Child Educ Pract Ed. 2014;99:111-6.

11. Postelnicu R, Evans L. Monitoring of the physical exam in sepsis. Curr Opin Crit Care. 2017;23:232-6. 
12. Hanson J, Lam SW, Alam S, Pattnaik R, Mahanta KC, Uddin Hasan M, Mohanty S, Mishra S, Cohen S, Day N, White N, Dondorp A. The reliability of the physical examination to guide fluid therapy in adults with severe falciparum malaria: an observational study. Malar J. 2013;12:348.

13. Ait-Oufella H, Lemoinne S, Boelle PY, Galbois A, Baudel JL, Lemant J, Joffre J, Margetis D, Guidet B, Maury E, Offenstadt G. Mottling score predicts survival in septic shock. Intensive Care Med. 2011;37:801-7.

14. Ait-Oufella H, Joffre J, Boelle PY, Galbois A, Bourcier S, Baudel JL, Margetis D, Alves M, Offenstadt G, Guidet B, Maury E. Knee area tissue oxygen saturation is predictive of 14-day mortality in septic shock. Intensive Care Med. 2012;38:976-83.

15. Coudroy R, Jamet A, Frat JP, Veinstein A, Chatellier D, Goudet V, Cabasson S, Thille AW, Robert R. Incidence and impact of skin mottling over the knee and its duration on outcome in critically ill patients. Intensive Care Med. 2015;41:452-9.

16. Akata T, Kanna T, Yoshino J, Higashi M, Fukui K, Takahashi S. Reliability of fingertip skinsurface temperature and its related thermal measures as indices of peripheral perfusion in the clinical setting of the operating theatre. Anaesth Intensive Care. 2004;32:519-29.

17. Rubinstein EH, Sessler DI. Skin-surface temperature gradients correlate with fingertip blood flow in humans. Anesthesiology. 1990;73:541-5.

18. Thompson MJ, Ninis N, Perera R, Mayon-White R, Phillips C, Bailey L, Harnden A, Mant D, Levin M. Clinical recognition of meningococcal disease in children and adolescents. Lancet. 2006;367:397-403.

19. Monnet X, Teboul JL. Passive leg raising: five rules, not a drop of fluid! Crit Care. 2015;19:18.

20. Cherpanath TG, Hirsch A, Geerts BF, Lagrand WK, Leeflang MM, Schultz MJ, Groeneveld AB. Predicting fluid responsiveness by passive leg raising: a systematic review and metaanalysis of 23 clinical trials. Crit Care Med. 2016;44:981-91.

21. Lu GP, Yan G, Chen Y, Lu ZJ, Zhang LE, Kissoon N. The passive leg raise test to predict fluid responsiveness in children - preliminary observations. Indian J Pediatr. 2015;82:5-12.

22. Maitland K, Kiguli S, Opoka RO, Engoru C, Olupot-Olupot P, Akech SO, Nyeko R, Mtove G, Reyburn H, Lang T, Brent B, Evans JA, Tibenderana JK, Crawley J, Russell EC, Levin M, Babiker AG, Gibb DM, Group FT. Mortality after fluid bolus in African children with severe infection. N Engl J Med. 2011;364:2483-95.

23. Maitland K, Pamba A, English M, Peshu N, Marsh K, Newton C, Levin M. Randomized trial of volume expansion with albumin or saline in children with severe malaria: preliminary evidence of albumin benefit. Clin Infect Dis. 2005;40:538-45.

24. Akech S, Ledermann H, Maitland K. Choice of fluids for resuscitation in children with severe infection and shock: systematic review. BMJ. 2010;341:c4416.

25. Wills BA, Nguyen MD, Ha TL, Dong TH, Tran TN, Le TT, Tran VD, Nguyen TH, Nguyen VC, Stepniewska K, White NJ, Farrar JJ. Comparison of three fluid solutions for resuscitation in dengue shock syndrome. N Engl J Med. 2005;353:877-89.

26. Dung NM, Day NP, Tam DT, Loan HT, Chau HT, Minh LN, Diet TV, Bethell DB, Kneen R, Hien TT, White NJ, Farrar JJ. Fluid replacement in dengue shock syndrome: a randomized, double-blind comparison of four intravenous-fluid regimens. Clin Infect Dis. 1999;29:787-94.

27. Ngo NT, Cao XT, Kneen R, Wills B, Nguyen VM, Nguyen TQ, Chu VT, Nguyen TT, Simpson JA, Solomon T, White NJ, Farrar J. Acute management of dengue shock syndrome: a randomized double-blind comparison of 4 intravenous fluid regimens in the first hour. Clin Infect Dis. 2001;32:204-13.

28. Cifra HL, Velasco JN. A comparative study of the efficacy of 6\%. Haes-Steril and Ringer's lactate in the management of dengue shock syndrome 555. Crit Care Shock. 2003;6:95-100.

29. Rivers E, Nguyen B, Havstad S, Ressler J, Muzzin A, Knoblich B, Peterson E, Tomlanovich M, Early Goal-Directed Therapy Collaborative Group. Early goal-directed therapy in the treatment of severe sepsis and septic shock. N Engl J Med. 2001;345:1368-77.

30. Maitland K, George EC, Evans JA, Kiguli S, Olupot-Olupot P, Akech SO, Opoka RO, Engoru C, Nyeko R, Mtove G, Reyburn H, Brent B, Nteziyaremye J, Mpoya A, Prevatt N, Dambisya CM, Semakula D, Ddungu A, Okuuny V, Wokulira R, Timbwa M, Otii B, Levin M, Crawley J, 
Babiker AG, Gibb DM. Exploring mechanisms of excess mortality with early fluid resuscitation: insights from the FEAST trial. BMC Med. 2013;11:68.

31. Andrews B, Muchemwa L, Kelly P, Lakhi S, Heimburger DC, Bernard GR. Simplified severe sepsis protocol: a randomized controlled trial of modified early goal-directed therapy in Zambia. Crit Care Med. 2014;42:2315-24.

32. Baker T, Schell CO, Lugazia E, Blixt J, Mulungu M, Castegren M, Eriksen J, Konrad D. Vital signs directed therapy: improving care in an intensive care unit in a low-income country. PLoS One. 2015;10:e144801.

33. Jacob ST, Banura P, Baeten JM, Moore CC, Meya D, Nakiyingi L, Burke R, Horton CL, Iga B, Wald A, Reynolds SJ, Mayanja-Kizza H, Scheld WM, Promoting Resource-Limited Interventions for Sepsis Management in Uganda Study Group. The impact of early monitored management on survival in hospitalized adult Ugandan patients with severe sepsis: a prospective intervention study. Crit Care Med. 2012;40:2050-8.

34. Andrews B, Semler MW, Muchemwa L, Kelly P, Lakhi S, Heimburger DC, Mabula C, Bwalya M, Bernard GR. Effect of an early resuscitation protocol on in-hospital mortality among adults with sepsis and hypotension: a randomized clinical trial. JAMA. 2017;318:1233-40.

35. Day NP, Phu NH, Bethell DP, Mai NT, Chau TT, Hien TT, White NJ. The effects of dopamine and adrenaline infusions on acid-base balance and systemic haemodynamics in severe infection. Lancet. 1996;348:219-23.

36. Mahmoud KM, Ammar AS. Norepinephrine supplemented with dobutamine or epinephrine for the cardiovascular support of patients with septic shock. Indian J Crit Care Med. 2012;16:75-80.

37. Pandey A, John BM. Capillary refill time. Is it time to fill the gaps? Med J Armed Forces India. 2013;69:97-8.

Open Access This chapter is licensed under the terms of the Creative Commons Attribution 4.0 International License (http://creativecommons.org/licenses/by/4.0/), which permits use, sharing, adaptation, distribution and reproduction in any medium or format, as long as you give appropriate credit to the original author(s) and the source, provide a link to the Creative Commons license and indicate if changes were made.

The images or other third party material in this chapter are included in the chapter's Creative Commons license, unless indicated otherwise in a credit line to the material. If material is not included in the chapter's Creative Commons license and your intended use is not permitted by statutory regulation or exceeds the permitted use, you will need to obtain permission directly from the copyright holder.

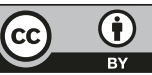

